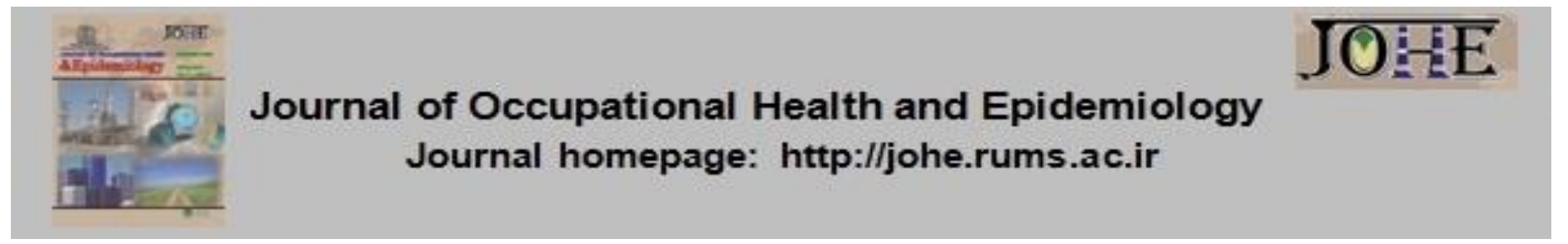

\title{
Prevalence of Musculoskeletal Disorders and Occupational Stress among Workers of an Engineering Company in Iran during the Covid-19 Pandemic, 2021: A Cross-Sectional Study
}

\author{
Elham Akhlaghi Pirposhteh ${ }^{1}$, Niloofar Sheibani², Atefeh Beheshti ${ }^{3}$, Nader Bakhshi $^{4}$, Ali Salehi Sahl \\ ${\text { Abadi }{ }^{*}}^{*}$
}

1. PhD Student in Occupational Health Engineering, Dept. of Occupational Health Engineering, School of Medical Sciences, Tarbiat Modares University, Tehran, Iran.

2. MSc in Ergonomics, Dept. of Occupational Health, School of Health, Tehran University of Medical Sciences, Tehran, Iran.

3. BSc in Occupational Health Engineering, Dept. of Occupational Health and Safety at Work Engineering, School of Public Health and Safety, Shahid Beheshti University of Medical Sciences, Tehran, Iran.

4. MSc in Environmental Management (HSE), Dept. of Environmental Engineering, Central Tehran Branch, Islamic Azad University, Tehran, Iran.

5. Assistant Prof., Workplace Health Promotion Research Center, Dept. of Occupational Health and Safety at Work, School of Public Health and Safety, Shahid Beheshti University of Medical Sciences, Tehran, Iran. \section{Citation: Akhlaghi Pirposhteh E, Sheibani N, Beheshti A, Bakhshi N, Salehi Sahl Abadi A.
Prevalence of Musculoskeletal Disorders and Occupational Stress among Workers of an Engineering Company in Iran during the Covid-19 Pandemic, 2021: A Cross-Sectional Study. CrossMark J Occu Health Epidemiol 2021; 10(3):183-92.}

\section{Article Info}

* Corresponding author:

Ali Salehi Sahl Abadi,

E-mail:

asalehi529@gmail.com

Article history

Received: Jun 2021

Accepted: Oct 2021

10.52547/johe.10.3.183

Print ISSN: 2251-8096 Online ISSN: 2252-0902

Peer review under responsibility of Journal of Occupational Health and Epidemiology

\section{Abstract}

Background: The present study aims to assess the prevalence of musculoskeletal disorders and occupational stress among workers of a factory in Iran during the COVID19 pandemic.

Materials and Methods: This cross-sectional study was conducted on all workers of an engineering company (140 participants). The tools used in the present study included the Perceived Stress Scale (PSS-14) Questionnaire and the Body Map Questionnaire. The participants were asked to respond to the questions according to their physical and mental status after the onset of the COVID-19 pandemic. The data were analyzed using SPSS V25.0.

Results: The most frequently reported musculoskeletal issues were related to the back $(61.4 \%)$ and neck $(53.6 \%)$ areas, while the lowest prevalence was related to elbows (17.9\%). A significant correlation was found between the final scores obtained from the PSS-14 and Body Map Questionnaires for the neck $(P=0.026)$ and shoulder $(P=0.009)$ areas. Besides, a significant correlation was found between the participants' gender and pain in the neck $(P=0.005)$ and shoulder $(P=0.048)$ areas. Furthermore, a significant correlation was found between marital status and pain in the pelvis $(P=0.034)$ and leg $(P$ $=0.007)$ areas as well as the thigh and knee $(P=0.017)$ areas.

Conclusions: The COVID-19 pandemic has affected various aspects of mental and physical health in occupational environments and has contributed to an increase in musculoskeletal pain and occupational stress levels. Thus, the adoption of effective strategies and the use of a comprehensive stress management program are suggested to prevent musculoskeletal disorders in occupational environments.

Keywords: COVID-19, Occupational Stress, Musculoskeletal Disorders, Occupational Health.

\section{Introduction}

In late December 2019, the COVID-19 pandemic was reported in Wuhan, China. Accordingly, in
January 2020, the Emergency Committee of the World Health Organization (WHO) declared a state of emergency based on the rise in the rate of

(C) The Author(s) 2021; All rights reserved. Published by Rafsanjan University of Medical Sciences Press. 
infections around the world [1]. COVID-19 is the seventh member of the Corona family of viruses that can infect humans and is considered an acute and deadly disease $[2,3]$. This disease is extremely contagious, with a single infected individual being able to spread the virus to at least three other individuals [4]. In Iran, the first officially reported death from COVID-19 was on February, 19, 2020 [5]. Based on the assessments and reports up till now, Iran is among the top 15 countries in terms of the total number of infections [6]. The COVID-19 pandemic has had a significant impact on the international community and has changed the everyday life of people everywhere [7]. Various restrictions have been introduced by countries around the world to control the spread of this virus. Besides, many individuals have lost their jobs as a result of the pandemic [8]. Companies have resorted to policies of using smartphones or working from home to reduce physical contact [9]. We can expect to see permanent changes in occupational environments after the COVID-19 pandemic is over. This is well reflected in the attempts made by certain companies to apply permanent policies of working from home even after the pandemic [10-12]. Some of the benefits of work from home policies include reduced commute times, increased productivity, improved motivation, better balancing of the worktime and everyday life, as well as more control over time management. In contrast, the drawbacks of such a policy include oversight problems, costs associated with working from home, communication issues (internet), and inability to separate work from the private life [13]. Besides, these limitations lead to considerable mental pressure. Accordingly, previous studies show that the pandemic can increase stress and anxiety even in healthy individuals [14]. Social isolation, inability to express and share problems with others, and inability to seek help from fellow peers can all contribute to negative emotions when working from home [15]. The social isolation and the distance caused by lockdowns and work from home policies have exerted detrimental effects on mental health, which have in turn led to increased digital media consumption as a means of evading the isolation. Besides, extended periods spent looking at a brightly lit screen can affect sleep patterns and durations with negative mental and physical health outcomes [16].

However, permanent workplace closures and continuous work from home policies are impossible to maintain. Some companies and organizations in Iran have followed the instructions given by the Iranian Ministry of Health and have attempted to regularly shift their workers from working at home to working in the workplace. Nevertheless, one can observe the negative effects of the pandemic and closures on mental and physical health even upon the use of these methods. For instance, a crosssectional study in Iran during the COVID-19 pandemic showed that government quarantine policies failed to account for workers' mental health. This is because many workers were forced to choose public transportation (for the use of personal automobiles being limited) or had to cope with the fear of being infected with the disease or becoming unemployed, ending in a potential financial disaster, which all exert mental pressure on these individuals [17]. A study by $\mathrm{Ho}$ et al [18] in Hong Kong showed a correlation between increased overall levels of stress reported during the pandemic and the implementation of bad policies of working conditions, shortage of available workforce, and insufficient amounts of personal protection equipment. A recent review by Brooks et al showed that quarantine measures could have negative mental health repercussions, such as PTSD symptoms as well as increased agitation and anger [19]. Highly stressful occupations can lead to burnout [20], thereby reducing job satisfaction and leading to job abandonment [21]. According to Havnen et al (2020) [22], the stress caused by the COVID-19 pandemic has a direct impact on depression. This means that individuals susceptible to anxiety have a higher risk of developing symptoms of depression when exposed to stress factors.

In addition to mental health risks posed by unsuitable policies during the pandemic, we can observe physical health risks. Musculoskeletal disorders are related to problems with muscles, tendons, synovium, peripheral nerves, joints, bones, ligaments, and blood vessels, which may result from repeated stress over time as well as sudden or acute traumas (such as a slip or a fall). Work-Related Musculoskeletal Disorders (WMSDs) are considered the most common cause of lost worktime, increased costs, and harm to human workforce [23]. WMSDs usually involve the back, neck, shoulders, elbows, wrists, fingers, and legs [24]. These disorders are preventable, so understanding their cause and prevalence is important for their control and prevention [25].

Experiencing musculoskeletal disorders (MSDs) reduces normal working hours to less than 8 hours daily [26]. Moreti et al [27] showed that the necessity of working from home during the pandemic increases the risk of WMSDs, especially in the vertebral column, due to the lack of ergonomic equipment [28] and physical activity [29]. Mozafari et al [30] determined the prevalence of musculoskeletal disorders and risk factors associated with these symptoms. The results of 
their study showed that the musculoskeletal issues had a high frequency among office workers (55.5\% of office workers had musculoskeletal disorders in a year). They concluded that musculoskeletal troubles have a high frequency among drivers and official workers. In another study, Alavi et al [31] investigated the association between individual, organizational, physical, and psychological factors and upper extremity MSDs (shoulders, elbows, hands, and wrists). Various risk factors in the workplace may contribute to MSDs in different parts of upper extremities. Hence, preventive interventions should consider ergonomic and office equipment modifications.

Studies on the prevalence of musculoskeletal disorders during the pandemic have mainly focused on the healthcare sector. This could be considered a strength in the present study as the target subjects are non-healthcare workers. Given the importance of mental and physical health of workers during the COVID-19 pandemic, the present study aims to assess the occupational stress and prevalence of musculoskeletal disorders among workers of an Iranian engineering company in 2021.

\section{Materials and Methods}

This descriptive-analytic cross-sectional study was carried out in 2021 in Iran. The study population included all administrative staff members of an engineering company (140 people), who were selected by the census method. Ethical approval for this study was obtained from Shahid Beheshti University of Medical Sciences, Tehran (IR.SBMU.PHNS.REC.1400.084). The participants who were willing to enter the study were required to have some criteria. These criteria included having at least one year of employment experience at the company, having no prior musculoskeletal disorders, having experienced no prior traumas or fractures, having no history of mental disorders, and having no prior experience of taking related drugs, such as sedatives. After informing the subjects on the objectives of the study and obtaining their satisfaction with participation, the required data were obtained by administering the questionnaires online via the intranet system of the company. Accordingly, the participants were asked to respond to the questions based on their physical and mental health status after the onset of the pandemic.

Data collection was performed using a Demographic Questionnaire, the PSS-14 Questionnaire, and the Body Map Questionnaire. Each data collection step has been detailed below. The Demographic Questionnaire: This questionnaire included demographic characteristics, including age, weight, height, marital status, level of education, as well as the participants' occupational role, including employment duration, rank, and the unit of the company currently working in.

The Perceived Stress Scale Questionnaire: The PSS-14 Questionnaire was devised by Cohen et al for the purpose of measuring general perceived stress in the past 30 days, being available in 4-, 10-, and 14-item variants [32]. In fact, the Farsi translated version of the PSS-14 Questionnaire was used in the present study. All 14 items in this questionnaire are scored on a Likert scale that ranges from 0 (never) to 4 (often) (Table 1). The highest and lowest obtainable scores are 56 and 0 , respectively. Besides, higher scores indicate the existence of stress. Reliability and validity of the Farsi version of this scale were verified in previous studies [33]. In addition, a Cronbach's alpha of 0.9 was reported for the Farsi version of this questionnaire by Maroufizadeh et al [34].

Table 1. Perceived Stress Scale (PSS-14) Questionnaire (35)

\begin{tabular}{|c|c|c|c|c|c|c|}
\hline & \multirow[b]{2}{*}{ Items } & \multicolumn{5}{|c|}{ Scores } \\
\hline & & $\begin{array}{l}\text { Never } \\
(0)\end{array}$ & $\begin{array}{l}\text { Almost } \\
\text { Never } \\
\text { (1) }\end{array}$ & $\begin{array}{l}\text { Sometimes } \\
\text { (2) }\end{array}$ & $\begin{array}{l}\text { Fairly } \\
\text { often } \\
(3)\end{array}$ & $\begin{array}{l}\text { Very } \\
\text { often } \\
(4)\end{array}$ \\
\hline 1 & $\begin{array}{l}\text { In the past month, how often were you upset at } \\
\text { something happening unexpectedly? }\end{array}$ & & & & & \\
\hline 2 & $\begin{array}{l}\text { In the past month, how often did you feel you were } \\
\text { unable to control important things in your life? }\end{array}$ & & & & & \\
\hline 3 & $\begin{array}{l}\text { In the past month, how often did you feel nervous and } \\
\text { stressed? }\end{array}$ & & & & & \\
\hline 4 & $\begin{array}{l}\text { In the past month, how often did you deal successfully } \\
\text { with irritating life hassles? }\end{array}$ & & & & & \\
\hline 5 & $\begin{array}{l}\text { In the past month, how often did you feel you were } \\
\text { effectively coping with important changes occurring to } \\
\text { your life? }\end{array}$ & & & & & \\
\hline 6 & $\begin{array}{l}\text { In the past month, how often did you feel confident of } \\
\text { your ability to handle your personal problems? }\end{array}$ & & & & & \\
\hline 7 & $\begin{array}{l}\text { In the past month, how often did you feel things were } \\
\text { going your way? }\end{array}$ & & & & & \\
\hline
\end{tabular}




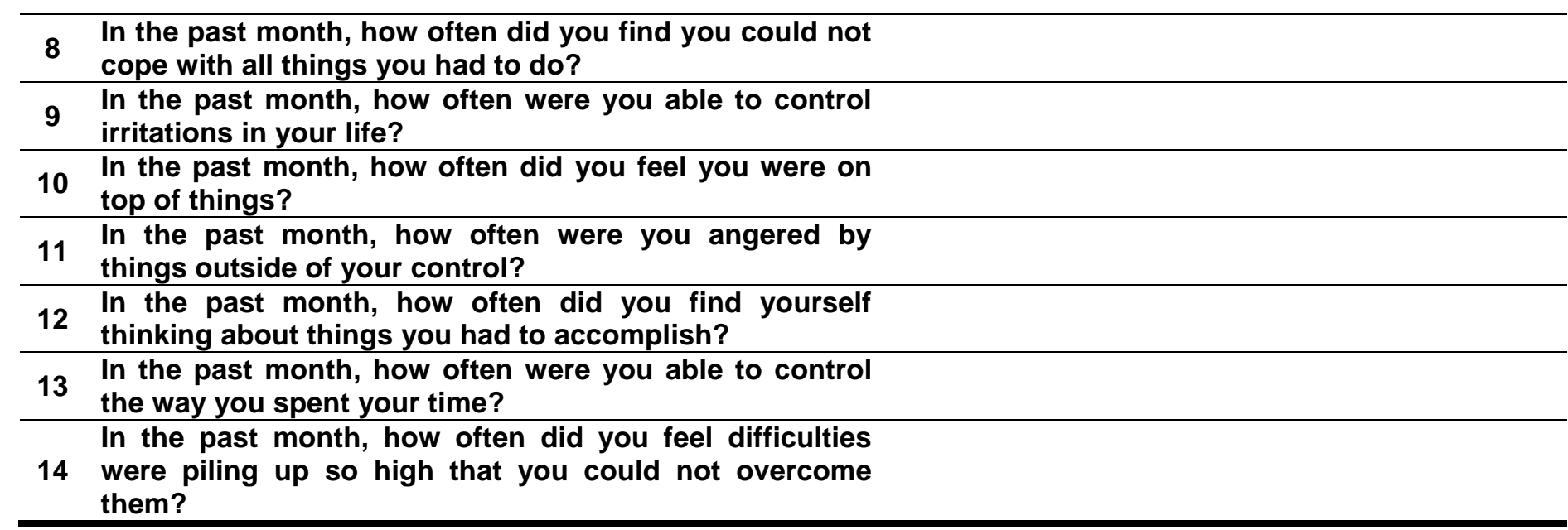

The Body Map Questionnaire: This questionnaire uses a map of the human body to determine the location and severity of the pain associated with musculoskeletal disorders based on the participants' mental perception of pain. Besides, the participants self-report the level of the pain they experience from 1 (no pain) to 9 (unbearable pain) $[23,36]$. This tool is part of the Nordic Questionnaire, with its Cronbach's alpha being based on the reliability of 0.896 and its suitable validity verified previously [37]. After data collection, those participants who had entered 0 or 1 in the questionnaire were considered pain-free, while those who entered a value over 1 were considered to be suffering pain. This tool is part of the Nordic questionnaire whose reliability and validity have been confirmed [38]. According to the studies of Kahraman et al [39], this scale has a high internal consistency coefficient, and its reliability coefficient was 0.896 through the Cronbach's alpha.

The participants in this study were asked to answer both questionnaires (the PSS-14 and Body Map Questionnaires) according to their current status during the COVID-19 pandemic.

The data were analyzed using SPSS V25.0. Besides, the Kolmogorov-Smirnov test was used to determine data distribution normality, which showed the BMI variable as the only variable with a normal distribution. The results were presented as descriptive statistics, including the mean, standard deviation, and frequency. Besides, correlation tests along with the Spearman's correlation coefficient were used for statistical analysis to determine the relationship between perceived stress and the scores obtained from the Body Map and the Demographic Questionnaires. In addition, all tests were conducted at a significance level of 0.05 .

\section{Results}

Table 2 shows evaluation results of the demographic variables. Accordingly, the participants had a mean age of $36.96 \pm 8.94$, which ranged from 23 to 58 years. Besides, the mean employment duration of the participants was 12.48 \pm 7.36 years, which ranged from 1 to 43 years.

Table 2. Evaluation of the demographic variables

\begin{tabular}{|c|c|c|}
\hline \multicolumn{2}{|c|}{ Variable } & Mean \pm SD / Percentage\%(n) \\
\hline \multicolumn{2}{|c|}{ Age (years) } & $36.96 \pm 8.94$ \\
\hline \multicolumn{2}{|c|}{ Work experience (years) } & $12.48 \pm 7.36$ \\
\hline \multicolumn{2}{|c|}{ Height $(\mathrm{cm})$} & $170.17 \pm 9.1$ \\
\hline \multicolumn{2}{|c|}{ Weight (kg) } & $73.93 \pm 15.07$ \\
\hline \multicolumn{2}{|c|}{ BMI } & $25.35 \pm 3.8$ \\
\hline \multirow{2}{*}{ Gender } & Female & $46.4 \%(n=65)$ \\
\hline & Male & $53.6 \%(n=75)$ \\
\hline \multirow{2}{*}{ Marital status } & Single & $36 \%(n=49)$ \\
\hline & Married & $64 \%(n=87)$ \\
\hline \multirow{3}{*}{ Educational level } & High School Diploma & $5.1 \%(n=7)$ \\
\hline & Bachelor's & $54.3 \%(n=75)$ \\
\hline & Master's and PhD & $40.6 \%(n=56)$ \\
\hline
\end{tabular}

Based on the results from the Body Map Questionnaire, the highest frequencies of the reported musculoskeletal issues were related to the back ( 86 cases), followed by the neck (75 cases), arms and shoulders (65 cases), thighs and knees (61 cases), hands and wrists (51 cases), legs (40 cases), pelvis (27 cases), and elbows (25 cases). Fig. 1 shows the mean score percentages obtained in the Body Map Questionnaire, as presented for each part of the body. 


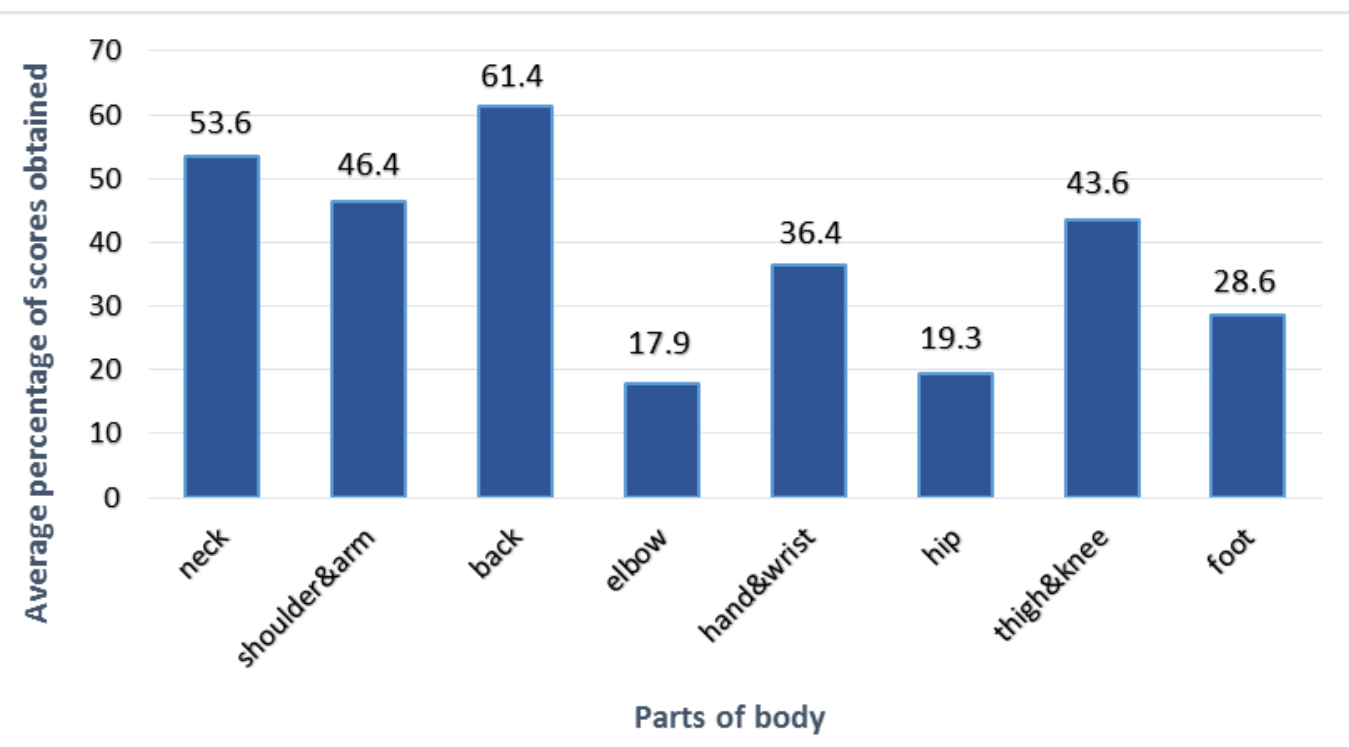

Fig. 1. The mean percentage of scores obtained in the Body Map Questionnaire for each part of the body

Fig. 2 shows the results of the descriptive statistics obtained from the PSS-14 Questionnaire. The lowest and highest scores obtained in this questionnaire were 4 and 47 , respectively, with the mean score of $18.81 \pm 7.24$.

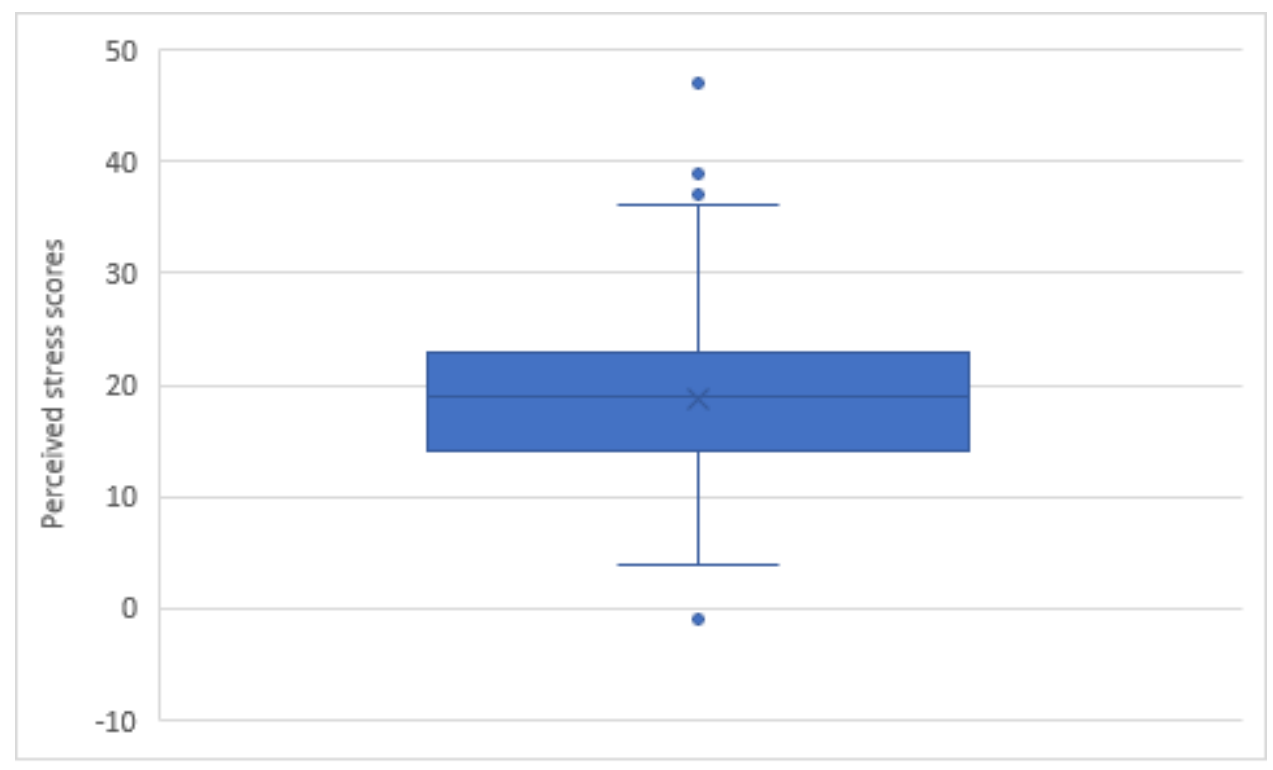

Fig. 2. Results of the PSS-14 Questionnaire

Table 3 shows the relationship between the scores obtained from the PSS-14 Questionnaire and the Body Map Questionnaire. Based on the analysis results, there was a statistically significant correlation between the scores of the PSS-14 and
Body Map Questionnaires for the neck $(P=0.026)$ and shoulders $(P=0.009)$. However, no statistically significant correlation was observed between stress scores and other parts of the body.

Table 3. Correlations between the scores of the PSS-14 and Body Map Questionnaires

\begin{tabular}{|c|c|c|c|c|c|c|c|c|c|}
\hline \multirow{2}{*}{\multicolumn{2}{|c|}{ Variables }} & \multicolumn{8}{|c|}{ Questionnaire Body Map } \\
\hline & & Legs & $\begin{array}{c}\begin{array}{c}\text { Thighs and } \\
\text { knees }\end{array} \\
\end{array}$ & Hip & $\begin{array}{c}\text { Hands and } \\
\text { wrists }\end{array}$ & Elbows & Waist & $\begin{array}{l}\text { Arms and } \\
\text { shoulders }\end{array}$ & Neck \\
\hline \multirow{2}{*}{$\begin{array}{l}\text { PSS_14 final } \\
\text { scores }\end{array}$} & $\begin{array}{l}\text { Spearman's } \\
\text { correlation }\end{array}$ & 0.114 & 0.161 & 0.041 & 0.135 & 0.075 & 0.161 & 0.0221 & 0.188 \\
\hline & P-value & 0.091 & 0.058 & 0.635 & 0.113 & 0.383 & 0.059 & $0.009^{*}$ & $0.026^{*}$ \\
\hline
\end{tabular}

${ }^{*} P<0.05$ 
According to Table 4 and the results of the Spearman's correlation test, there was no statistically significant correlation between demographic variables (age, weight, height, marital status, and level of education) and the scores obtained from the perceived stress questionnaire. However, a significant correlation was observed between demographic variables and the scores obtained from the Body Map Questionnaire. This showed a significant correlation between the BMI and neck pain $(P=0.046)$, participants' gender and neck pain $(P=0.005)$, participants' gender and pain in the shoulders and arms $(P=0.048)$, and the level of education and pain in the shoulders and arms $(P=0.040)$. Besides, a significant correlation was observed between marital status and pain in the pelvis $(P=0.034)$, legs $(P=0.007)$, as well as thighs and knees $(P=$ 0.017).

Table 4. Correlations between demographic variables and final scores of the PSS-14 and Body Map Questionnaires

\begin{tabular}{|c|c|c|c|c|c|c|c|c|c|c|}
\hline \multirow{2}{*}{\multicolumn{2}{|c|}{ Variables }} & \multirow{2}{*}{$\begin{array}{c}\text { PSS } \\
14 \\
\text { final } \\
\text { score }\end{array}$} & \multicolumn{8}{|c|}{ Body Map } \\
\hline & & & Legs & $\begin{array}{c}\text { Thighs } \\
\text { and }\end{array}$ & Hip & $\begin{array}{l}\text { Hands } \\
\text { and }\end{array}$ & Elbows & Waist & $\begin{array}{c}\text { Arms } \\
\text { and }\end{array}$ & Neck \\
\hline \multirow[t]{2}{*}{ Age } & $\begin{array}{l}\text { Spear } \\
\text { Corre }\end{array}$ & 0.038 & -0.061 & 0.055 & 0.027 & 0.025 & 0.036 & -0.123 & -0.052 & -0.148 \\
\hline & P-value & .659 & 0.475 & 0.523 & 0.754 & 0.766 & 0.675 & 0.149 & 0.543 & 0.081 \\
\hline \multirow[t]{2}{*}{ BMI } & $\begin{array}{l}\text { Spearman's } \\
\text { Correlation }\end{array}$ & .015 & 0.119 & 0.067 & 0.016 & -0.106 & -0.082 & -0.128 & -0.133 & -0.170 \\
\hline & P-value & 0.863 & 0.162 & 0.434 & 0.852 & 0.213 & 0.340 & 0.134 & 0.120 & $0.046^{*}$ \\
\hline \multirow{2}{*}{$\begin{array}{c}\text { Work } \\
\text { experience }\end{array}$} & $\begin{array}{l}\text { Spearman's } \\
\text { Correlation }\end{array}$ & -0.57 & -0.112 & 0.144 & 0.147 & 0.076 & 0.004 & -0.061 & -0.025 & -0.04 \\
\hline & P-value & 0.526 & 0.207 & 0.104 & 0.097 & 0.394 & 0.967 & 0.492 & 0.783 & 0.650 \\
\hline \multirow{2}{*}{ Gender } & $\begin{array}{l}\text { Spearman's } \\
\text { Correlation }\end{array}$ & -0.126 & 0.113 & -0.048 & -0.053 & -0.158 & -0.015 & -0.149 & -0.167 & -0.235 \\
\hline & P-value & 0.138 & 0.183 & 0.569 & 0.533 & 0.062 & 0.863 & 0.078 & 0.048 & $0.005^{\star}$ \\
\hline \multirow{2}{*}{$\begin{array}{c}\text { Educational } \\
\text { level }\end{array}$} & $\begin{array}{l}\text { Spearman's } \\
\text { Correlation }\end{array}$ & 0.042 & 0.004 & -0.059 & -0.144 & -0.29 & -0.029 & 0.021 & 0.175 & -0.044 \\
\hline & P-value & 0.623 & 0.960 & 0.495 & 0.183 & 0.736 & 0.738 & 0.805 & $0.040^{*}$ & 0.612 \\
\hline \multirow{2}{*}{$\begin{array}{l}\text { Marital } \\
\text { status }\end{array}$} & $\begin{array}{l}\text { Spearman's } \\
\text { Correlation }\end{array}$ & 0.143 & 0.228 & 0.204 & 0.182 & 0.044 & 0.040 & 0.489 & 0.166 & 0.009 \\
\hline & P-value & 0.099 & $0.007^{*}$ & $0.017^{*}$ & $0.034^{*}$ & 0.615 & 0.645 & 0.060 & 0.053 & 0.915 \\
\hline
\end{tabular}

${ }^{*} P<0.05$

\section{Discussion}

Based on the results, the highest frequencies of the reported musculoskeletal issues were related to the back (61.4\%) and the neck (53.6\%). This was consistent with the results of Celenay et al [40] who reported that back and neck issues were the most frequently reported musculoskeletal disorders during the COVID-19 pandemic. The findings of the present study indicate the significant effect of the COVID-19 pandemic on the prevalence of these disorders especially in the neck, back, shoulders, and elbows. Nodoushan et al [41] reported a significant rise in musculoskeletal disorders after the onset of the pandemic and observed an increase in the prevalence of neck pain from 36 to $55 \%$. Disser et al conducted a study to evaluate musculoskeletal repercussions of the COVID-19 pandemic and showed direct and indirect effects of the virus on multiple body systems, including the musculoskeletal system. Disser et al suggested the use of rehabilitation programs, including aerobic and resistance exercises for improving strength and reducing fatigue, which would benefit skeletal muscles, bones, joints, and the cardiovascular system of individuals infected with the virus [42]. Given the evidence presented, the higher prevalence of musculoskeletal disorders in the back, neck, shoulders and knees is more likely due to the 8hour daily shifts, in which workers are in unsuitable working positions, involving the repeated bending of the neck and the vertebral column, prolonged static positions, or small movements repeated many times. When muscles are repeatedly held in a special position, muscular imbalance is created in the related area, which leads to more pain reported by the individual [43]. These conditions are compounded by stressful social and psychological factors related to both the pandemic and job insecurity.

The lowest and highest scores obtained in the PSS-14 Questionnaire were 4 and 47, respectively, with the mean score of $18.81 \pm 7.24$. The lowest occupational stress score reported in 
the studies by Wang et al [44] and Ortega-Galán et al [45] were $18 \pm 4.1$ and $25.98 \pm 9.16$, respectively. They reported a high prevalence of occupational stress among the workers they studied. Most studies conducted during the COVID-19 pandemic report increased levels of occupational stress in this period.

Talaee et al reported that occupational stress and burnout were high among workers after the COVID-19 pandemic [46]. Hall et al investigated the effect of the COVID-19 pandemic on the mental health of the individuals working in the healthcare industry. Accordingly, they showed that the spread of this virus caused clinical and nonclinical stress among individuals due to the fear of death, fear of infecting family members, and the reality of losing colleagues. Preliminary evidence after the COVID-19 pandemic suggests that this global issue will have short-term and long-term effects on the mental health of workers [47].

The study of Gholami et al on the effects of COVID-19 pandemic on job stress and mental workload showed that COVID-19 pandemic increased severity of job stress [48]. The results of this study were in line with those of the present one. Besides, Rahmani et al showed that the COVID-19 pandemic increased coronary anxiety and burnout [49]. COVID-19 pandemic has affected various physical and mental dimensions of people in the workplace. Therefore, psychological interventions are necessary to improve mental health of employees during and after the COVID19 pandemic.

A review of the literature on this subject indicates that psychometric analysis of the perceived stress index among various subjects has always been at the center of attention for many researchers. Stress is an effective factor in developing healthrelated issues in a way that an individual under stress is no longer able to perform their societal and familial obligations. Said et al [50] reported that after the COVID-19 pandemic, three quarters of the Egyptian workers suffered from occupational stress due to the increase in almost all forms of physical, emotional, and social stressors related to work and employment, which compounded the occupational stress already present. Besides, they suggested some solutions for reducing occupational stress. In the same vein, research shows that occupational stressors contribute to mistakes or unsafe behaviors by workers due to the reduced concentration, distractions, forgetfulness, doubtfulness, impaired decision making, and pressures of their responsibility [51]. According to the findings of the present study, there was a statistically significant correlation between PSS-14 Questionnaire scores and Body
Map scores for the neck $(P=0.026)$ and shoulder $(P=0.009)$ areas. In addition, scores for the back, thighs, and knees were near significance values ( $P$ $=0.058$ ). The strongest correlation was observed between the scores of the neck area and the final scores of the PSS-14 Questionnaire. The results of Table 3 reflect the importance of physical and mental health in the participants because perceived pain increased in various body areas along with the increase in the final scores of the PSS-14 Questionnaire. The study by Joseph et al showed that the limitations imposed on social interactions increased occupational stress, and the risks involved in necessary outdoor activities increased the levels of inflammatory markers and pain modulators, thereby affecting pain thresholds. This was especially true for the individuals who previously suffered from the chronic pain syndrome. In addition, research indicates that limited physical activity due to lockdowns contributes to increased musculoskeletal pain, most notably lower and upper back pain [52].

Results of the Spearman's correlation coefficient test showed no statistically significant correlation between demographic variables and the scores of the perceived stress questionnaire. The study by Rashidi et al (2020) showed no significant correlation between any subscales related to occupational stress or general health and demographic variables $(p<0.05)$ [53]. OrtegaGalán et al conducted a study on healthcare professionals in Spain using the PSS-14 Questionnaire, which showed no significant correlation between age, gender, or employment duration and occupational stress. However, they observed a significant correlation between marital status and occupational stress [45]. Research shows a significant correlation between demographic variables, such as participants' gender and signs of stress, anxiety, and depression among workers during the COVID-19 pandemic [54].

A significant correlation was observed between demographic variables and the scores obtained from the Body Map questionnaire. Besides, a significant correlation was observed between the $\mathrm{BMI}$ and pain in the neck area $(P=0.046)$, as increases in the BMI resulted in increased pain in the neck. Similarly, a significant correlation was observed between participants' gender and pain in the neck $(P=0.005)$, as well as the shoulders and arms $(P=0.048)$. In addition, a significant correlation was observed between marital status and pain in the pelvis $(P=0.034)$, legs $(P=0.007)$, as well as thighs and knees $(P=0.017)$. These results were consistent with those of Beheshti et al and Khademol-hoseyni et al [55, 56]. Jafari- 
Nodoushan et al reported that marital status and participants' gender had a significant correlation with musculoskeletal disorders in various parts of the body [41]. This may be due to the fact that women have smaller figures, lower muscle mass, and generally weaker muscles than men. Besides, it could due to women's continued work at home after their daily jobs, or because of having multiple pregnancies.

Against this backdrop, the importance of mental and physical health during the COVID-19 pandemic becomes clear. Besides, addressing this issue using suitable solutions can result in improved job satisfaction and reduced musculoskeletal disorders, thereby reducing costs and increasing productivity [27]. This is the reason why conducting research in this field is vital. The majority of musculoskeletal issues can be alleviated using suitable ergonomic interventions, most notably, proper training in ergonomic requirements in a particular occupation. Studies stress positive effects of training on awareness levels among workers. In addition, ergonomic consultation and financial support for purchasing suitable ergonomic equipment can be effective interventions in reducing musculoskeletal disorders among workers.

The COVID-19 pandemic affects mental and physical health of workers in most occupational environments. Besides, it leads to increased occupational stress and a high prevalence of musculoskeletal disorders especially in the back and neck areas. Accordingly, effective measures must be taken to cushion these effects, through providing social support to workers, providing financial aid to workers, providing suitable personal protection equipment (shields, masks, gloves, etc.) in accordance with guidelines given by relevant organizations (WHO, OSHA, and NIOSH), providing training in musculoskeletal disorders, reducing or controlling stress in work environments during the pandemic, and resorting to work from home policies when possible.

One of the limitations of the present study was the cross-sectional nature of its data and the lack of an overall mental health assessment of the participants, especially before the onset of the pandemic. Another limitation was that the potential effects of other harmful occupational hazards, or the effects of the participants' personal lives on their mental health were not taken into account. It is worth noting that there are different views on people's perception, understanding, and interaction with the virus and the pandemic. Accordingly, the participants could have been biased when answering these questionnaires. Thus, it is suggested that, in future studies, musculoskeletal disorders be assessed in other occupational groups using other Nordic questionnaires to compare the results.

\section{Conclusion}

The COVID-19 pandemic has affected mental and physical health of workers in most occupational environments and has led to increased occupational stress and a higher prevalence of musculoskeletal disorders, especially in the back and neck areas. In the present study, a significant correlation was found between the final scores obtained from PSS-14 and Body Map Questionnaire for the neck and shoulder areas. Thus, it is suggested that effective strategies be adopted for preventing musculoskeletal disorders, and that comprehensive stress management programs be devolved in this regard.

\section{Acknowledgement}

The authors would like to thank all individuals who contributed to the completion of this research, including the management, the head of HSE, and the personnel of the company employed in this research. This study was approved by Shahid Beheshti University of Medical Sciences, Workplace Health Promotion Research Center (WHPRC), Tehran (Grant no. 30103).

\section{Conflict of interest: None declared.}

\section{References}

1. Sarailoo M, Matin S, Vosoughi M, Dargahi $A$, Gholizadeh H, Damavandi MR, et al. Investigating the relationship between occupation and SARS-CoV2. Work 2021; 68(1):27-32.

2. Zhou $P$, Yang XL, Wang XG, Hu B, Zhang L, Zhang $W$, et al. A pneumonia outbreak associated with a new coronavirus of probable bat origin. Nature 2020; 579(7798):270-3.

3. Wu F, Zhao S, Yu B, Chen YM, Wang W, Song $Z G$, et al. A new coronavirus associated with human respiratory disease in China. Nature 2020; 579(7798):265-9.

4. Karami C, Normohammadi A, Dargahi A, Vosoughi $M$, Zandian $H$, Jeddi $F$, et al. Investigation of SARS-CoV-2 virus on nozzle surfaces of fuel supply stations in North West of Iran. Sci Total Environ 2021; 780:146641.

5. Dargahi A, Jeddi F, Vosoughi M, Karami C, Hadisi A, Ahamad Mokhtari S, et al. Investigation of SARS CoV-2 virus in environmental surface. Environ Res 2021; 195:110765.

6. Seddighi $\mathrm{H}$. The Performance of the Iranian Red Crescent by launching Testing Centers for 
the Coronavirus Disease. Disaster Med Public Health Prep 2020; 14(6):e45.

7. Ratten V. Coronavirus (covid-19) and entrepreneurship: changing life and work landscape. J Small Bus Entrep 2020; 32(5):50316.

8. Kochhar R. Unemployment rose higher in three months of COVID-19 than it did in two years of the Great Recession. Washington, D.C., United States: Pew Research Center; 2020 Jun.

9. Raišienè $A G$, Rapuano $V$, Varkulevičiūtè $K$, Stachová K. Working from Home -Who Is Happy? A Survey of Lithuania's Employees during the COVID-19 Quarantine Period. Sustain 2020; 12(13):5332.

10. Byers D. Twitter employees can work from home forever, CEO says. [Internet]. 2020 May. Available from: https://www.nbcnews.com/tech/technews/twitter-employees-can-work-homeforever-ceo-says-n1205346

11. Conger K. Facebook Starts Planning for Permanent Remote Workers. 2020 May. Available from: https://www.nytimes.com/2020/05/21/technolog y/facebook-remote-work-coronavirus.html

12. De' R, Pandey N, Pal A. Impact of digital surge during Covid-19 pandemic: A viewpoint on research and practice. Int $\mathrm{J}$ Inf Manage 2020; 55:102171.

13. Heathfield SM. The Pros and Cons of a Flexible Work Schedule. 2020 Jan. Available from: https://www.thebalancecareers.com/advantages -and-disadvantages-of-flexible-work-schedules1917964

14. Taylor S. Understanding and treating health anxiety: A cognitive-behavioral approach. Cogn Behav Pract 2004; 11(1):112-23.

15. Mann S, Holdsworth L. The psychological impact of teleworking: stress, emotions and health. New Technol Work Employ 2003; 18(3):196-211.

16. Majumdar P, Biswas A, Sahu S. COVID-19 pandemic and lockdown: cause of sleep disruption, depression, somatic pain, and increased screen exposure of office workers and students of India. Chronobiol Int 2020; 37(8):1191-200.

17. Seddighi H, Dollard MF, Salmani I. Psychosocial Safety Climate of Employees During the COVID-19 Pandemic in Iran: A Policy Analysis. Disaster Med Public Health Prep 2020; 1-7.

18. Wong EL, Ho KF, Wong SY, Cheung AW, Yeoh EK. Workplace safety and coronavirus disease (COVID-19) pandemic: survey of employees. Bull World Health Organ 2020; doi:10.2471/BLT.20255893.

19. Brooks SK, Webster RK, Smith LE, Woodland L, Wessely S, Greenberg N, et al. The psychological impact of quarantine and how to reduce it: rapid review of the evidence. Lancet 2020; 395(10227):912-20.
20. Embriaco N, Papazian L, Kentish-Barnes N, Pochard F, Azoulay Elie. Burnout syndrome among critical care healthcare workers. Curr Opin Crit Care 2007; 13(5):482-8.

21. Dyrbye LN, Shanafelt TD, Johnson PO, Johnson LA, Satele D, West CP. A crosssectional study exploring the relationship between burnout, absenteeism, and job performance among American nurses. BMC Nurs 2019; 18:57.

22. Havnen A, Anyan F, Hjemdal O, Solem S, Gurigard Riksfjord M, Hagen K. Resilience Moderates Negative Outcome from Stress during the COVID-19 Pandemic: A ModeratedMediation Approach. Int J Environ Res Public Health 2020; 17(18):6461.

23. Choobineh A. The Methods of Posture Analyses in Job Ergonomics. Hamadan: Fanavaran; 2013.

24. Moussavi Najarkola SA. The effect of age on the prevalence of upper extremity musculoskeletal disorders (UEMSDS) in Qaem Shahr weaving factory, Iran. Payesh 2007; 6(2):109-17.

25. Entzel P, Albers J, Welch L. Best practices for preventing musculoskeletal disorders in masonry: stakeholder perspectives. Appl Ergon 2007; 38(5):557-66.

26. Rahman NIA, Ismail S, Ali RM, Alattraqchi AG, Dali W, Umar BU, et al. Stress among first batch of MBBS students of Faculty of Medicine and Health Sciences, Universiti Sultan Zainal Abidin, Malaysia: when final professional examination is knocking the door. Int Med $\mathrm{J}$ 2015; 22(4):1-6.

27. Moretti A, Menna F, Aulicino M, Paoletta M, Liguori S, Iolascon G. Characterization of Home Working Population during COVID-19 Emergency: A Cross-Sectional Analysis. Int J Environ Res Public Health 2020; 17(17):6284.

28. Pillastrini P, Mugnai R, Bertozzi L, Costi S, Curti $S$, Guccione A, et al. Effectiveness of an ergonomic intervention on work-related posture and low back pain in video display terminal operators: a 3 year cross-over trial. Appl Ergon 2010; 41(3):436-43.

29. Shariat A, Cardoso JR, Cleland JA, Danaee M, Ansari NN, Kargarfard M, et al. Prevalence rate of neck, shoulder and lower back pain in association with age, body mass index and gender among Malaysian office workers. Work 2018; 60(2):191-9.

30. Mozafari A, Vahedian M, Mohebi S, Najafi M. Work-related musculoskeletal disorders in truck drivers and official workers. Acta Med Iran 2015; 53(7):432-8.

31. Alavi SS, Abbasi M, Mehrdad R. Risk Factors for Upper Extremity Musculoskeletal Disorders among Office Workers in Qom Province, Iran. Iran Red Crescent Med J 2016; 18(10):e29518.

32. Cohen S, Kamarck T, Mermelstein R. A global measure of perceived stress. J Health Soc Behav 1983; 24(4):385-96. 
33. Maroufizadeh S, Foroudifard F, Navid B, Ezabadi Z, Sobati B, Omani-Samani R. The Perceived Stress Scale (PSS-10) in women experiencing infertility: A reliability and validity study. Middle East Fertil Soc J 2018; 23(4):4569.

34. Maroufizadeh S, Zareiyan A, Sigari N. Reliability and validity of Persian version of perceived stress scale (PSS-10) in adults with asthma. Arch Iran Med 2014; 17(5):361-5.

35. Cohen S, Kamarck T, Mermelstein R. Perceived Stress Scale. J Health Soc Behav 1983; 24:285.

36. Karami Matin B, Mehrabi Matin A, Ziaei M, Nazari Z, Yarmohammadi H, Gharagozlou F. Risk assessment of cumulative trauma disorders in Quarry and Stone Industries workers Kermanshah in 1392. J Ergon 2013; 1(2):28-35.

37. Kahraman T, Genç A, Göz E. The Nordic Musculoskeletal Questionnaire: cross-cultural adaptation into Turkish assessing its psychometric properties. Disabil Rehabil 2016; 38(21):2153-60.

38. Kuorinka I, Jonsson B, Kilbom A, Vinterberg $H$, Biering-Sørensen F, Andersson G, et al. Standardised Nordic questionnaires for the analysis of musculoskeletal symptoms. Appl Ergon 1987; 18(3):233-7.

39. Kahraman T, Genç A, Göz E. The Nordic Musculoskeletal Questionnaire: cross-cultural adaptation into Turkish assessing its psychometric properties. Disabil Rehabil 2016; 38(21):2153-60.

40. Toprak Celenay S, Karaaslan Y, Mete O, Ozer Kaya D. Coronaphobia, musculoskeletal pain, and sleep quality in stay-at home and continued-working persons during the 3-month Covid-19 pandemic lockdown in Turkey. Chronobiol Int 2020; 37(12):1778-85.

41. Jafari-Nodoushan AA, Bagheri G, Mosavi Nodoushan F. Effect of COVID-19 virus on Prevalence of Musculoskeletal Disorders of Faculty Members of Yazd University. J Ergon 2020; 8(3):1-12.

42. Disser NP, De Micheli AJ, Schonk MM, Konnaris MA, Piacentini AN, Edon DL, et al. Musculoskeletal Consequences of COVID-19. J Bone Joint Surg Am 2020; 102(14):1197-204.

43. Akhlaghi Pirposhteh E, Karim A, Salehi Sahl Abadi A. Evaluation the Prevalence of Musculoskeletal Disorders among the Medical Staff of Selected Hospitals of Shahid Beheshti University of Medical Sciences in 2018. Safe Promot Inj Prev 2019; 7(2):69-77.

44. Wang LQ, Zhang M, Liu GM, Nan SY, Li T, Xu $L$, et al. Psychological impact of coronavirus disease (2019) (COVID-19) epidemic on medical staff in different posts in China: A multicenter study. J Psychiatr Res 2020; 129:198-205.
45. Ortega-Galán ÁM, Ruiz-Fernández MD, Lirola MJ, Ramos-Pichardo JD, Ibáñez-Masero $\mathrm{O}$, Cabrera-Troya J, et al. Professional Quality of Life and Perceived Stress in Health Professionals before COVID-19 in Spain: Primary and Hospital Care. Healthcare 2020; $8(4): 484$

46. Talaee $N$, Varahram $M$, Jamaati $H$, Salimi $A$, Attarchi M, Kazempour Dizaji M, et al. Stress and burnout in health care workers during COVID-19 pandemic: validation of a questionnaire. Z Gesundh Wiss 2020; 1-6.

47. Hall $H$. The effect of the COVID-19 pandemic on healthcare workers' mental health. JAAPA 2020; 33(7):45-8.

48. Gholami A, Sadeghi Yarandi $M$, Ghasemi $M$, Sadeghi Yarandi M, Ghasemi Koozekonan A, Soltanzadeh A. Effect of coronavirus epidemic on job stress and mental workload: A longitudinal study in a chemical industry. Iran Occup Health J 2020; 17(COVID-19 2020):81-9.

49. Rahmani $R$, Sargazi V, Shirzaei Jalali $M$, Babamiri M. Relationship between COVID-19caused Anxiety and Job Burnout among Hospital Staff: A Cross-sectional Study in the Southeast of Iran. J Occup Hyg Eng 2020; 7(4):61-9.

50. Said RM, EI-Shafei DA. Occupational stress, job satisfaction, and intent to leave: nurses working on front lines during COVID-19 pandemic in Zagazig City, Egypt. Environ Sci Pollut Res Int 2021; 28(7):8791-801.

51. Mukosolu O, Ibrahim F, Rampal L, Ibrahim N. Prevalence of Job Stress and Its Associated Factors among Universiti Putra Malaysia Staff. Malays J Med Health Sci 2015; 11(1):27-38.

52. Joseph SJ, Shoib S, Sg T, Bhandari SS. Psychological concerns and musculoskeletal pain amidst the COVID-19 lockdown. Open J Psychiatry Allied Sci 2020; 11(2):137-9.

53. Rashidi MA, PiranAghl MR, Ahmadi O, Pournajaf A, Seififard $M$, Kazemi $M$, et al. Occupational Fatigue and Sleep Quality: A Comparison Between Nurses Working in Various Wards of Public Hospitals. J Adv Med Biomed Res 2020; 28(131):336-45.

54. Xiao X, Zhu X, Fu S, Hu Y, Li X, Xiao J. Psychological impact of healthcare workers in China during COVID-19 pneumonia epidemic: A multi-center cross-sectional survey investigation. J Affect Disord 2020; 274:405-10.

55. Beheshti M, Hajizadeh R, Khodaparast E, Shojaei R, Ranjbar E. The role of workload and job satisfaction in general health of industrial workers in Gonabad, Iran, in 2015. J Occu Health Epidemiol 2014; 3(1):17-25.

56. Khademol-Hoseyni SM, Nouri JM, Khoshnevis MA, Ebadi A. Consequences of nursing procedures measurement on job satisfaction. Iran J Nurs Midwifery Res 2013; 18(2):123-7. 